Anuario Latinoamericano

Ciencias Políticas

y Relaciones Internacionales

vol. 3, 2016

pp. $107-124$

DOI: $10.17951 / \mathrm{al} .2016 .3 .107$

\section{cambios constitucionales recientes en materia de religión y política en México}

\author{
The concept of secularity in the context of recent \\ constitutional changes in the matter of religion \\ and politics in Mexico
}

\author{
Marta Wójtowicz-Wcisło \\ INSTITUTO DE ESTUDIOS IBÉRICOS E IBEROAMERICANOS, \\ UNIVERSIDAD DE VARSOVIA, POLONIA \\ $\triangle$ marta.noj@gmail.com
}

\section{RESUMEN}

En el artículo se presentan distintos conceptos de laicidad desarrollados desde México en el contexto de los últimos cambios constitucionales en materia de relación entre política y religión: la modificación al artículo 40 que establece el carácter laico del Estado y al artículo 24 que amplía el contenido del derecho a libertad religiosa. Con base en la discusión de estas reformas, se enfocan posturas de actores principales acerca del problema de laicidad y límites de la libertad religiosa.

PALABRAS CLAVE: laicidad, Estado laico, politica y religión, libertad religiosa, relaciones Estado-Iglesia.

\section{ABSTRACT \\ The article focuses on the positions of the main actors concerning the problem of secularity and the limits of freedom of religion in the context of constitutional changes that have been approved recently in México, such as the: modification of the article 40 that establishes explicitly a secular character of the Mexican State and the modification of the article 24 that broadens freedom of religion.}

KEYWORDS: secularity, secular state, politics and religion, freedom of religion, church-state relations.

\section{Introducción}

El tema de relaciones Estado-Iglesia(s) en México es de especial importancia. La Iglesia católica ha desempeñado un papel preponderante en la vida socio- 
Dossier América Latina: política y religión política a partir de la época colonial, permaneciendo como la institución más significante en el periodo de la independencia, ante un Estado incipiente. Las relaciones Estado-Iglesia(s), especialmente arduas y tormentosas en este país, han sido objeto de numerosos estudios.

El tema de interferencia de la esfera religiosa y política de por sí tiene un significado eminente, ya que atañe a múltiples, si no a todas, cuestiones sociales, si consideramos que es precisamente por medio de la religión y la política por las que se pretende regular la conducta del ser humano, en sus dimensiones vitales. Los últimos cambios constitucionales en la esfera de religión y política en México, a saber, la modificación al artículo 40, aprobada en 2012, que establece el carácter laico de la República, y al artículo 24 que amplía el contenido del derecho a libertad religiosa, aprobada en 2013, han sido estudiadas por los académicos en México. El resultado de estos esfuerzos se presenta en gran medida en el trabajo colectivo titulado La República laica y sus libertades. Las reformas a los artículos 24 y 40 constitucionales, con Estudio introductorio de Roberto J. Blancarte, que plantea el problema del significado y el alcance de la República laica desde la perspectiva de derechos humanos.

El objetivo del presente artículo es exponer distintos conceptos de laicidad desarrollados desde México, con base en el discurso político de principales actores, en el contexto de los cambios constitucionales mencionados. Se quiere demostrar que el sentido de laicidad que prevaleció como efecto de las reformas se mantiene compatible con la tradición político-jurídica mexicana, cultivada sobre todo a partir de la mitad del siglo XIX, de separar estrictamente la esfera religiosa y política, rechazando las pretensiones de la Iglesia católica del reconocimiento de la identidad católica del pueblo mexicano.

En la primera parte del artículo se da cuenta de la evolución del modelo de relaciones Estado-Iglesia(s) en México, para pasar a la discusión de reformas recientes con base en debates de congresistas, enfocándose en las posturas de los partidos principales (Partido de la Revolución Institucional, PRI; Partido de Acción Nacional, PAN; Partido de la Revolución Democrática, PRD y Partido del Trabajo, PT) acerca del problema de laicidad y límites de la libertad religiosa. Se examina también la posición de la Iglesia católica en dichas cuestiones, así como la posición de los críticos a la reforma del art. 24. En la última parte se presentan conclusiones.

\section{Las relaciones Estado-Iglesia en México}

En el curso de la Guerra de la Reforma (1857-1861) en México se asentaron las bases del Estado laico, que restringiría la esfera político-social de la influencia de creencias religiosas. Los gobiernos revolucionarios del siglo XX intentaron suprimir la hegemonía de la Iglesia católica y luego impedir su funcionamiento en todas las esferas de la vida. Sin embrago, tras la Guerra Cristera tuvieron que pactar con el Vaticano un modus vivendi, de acuerdo 
con el cual leyes anticatólicas se ejercían con más benevolencia o devenían letra muerta. La Iglesia católica se hacía cada vez más presente y activa en la vida política, llegando a superar el modus vivendi en los años 1980. Por un lado, el Episcopado apoyaba a los gobiernos civiles en materias que concordaban con la doctrina católica y contenía corrientes de contestación que buscaban un cambio radical; por el otro, criticaba políticas contrarias a la doctrina, denunciaba fraudes, demandaba cambios democráticos, saneamiento de la vida política y estimulaba al electorado. El cambio del modelo jurídico de relaciones Estado-Iglesias en México en los años 1991-1992 reconfiguró el marco jurídico mexicano de acuerdo con exigencias del derecho internacional y estándares de la democracia liberal. Este cambio comprendió la supresión de más importantes limitaciones a la libertad religiosa y libertad de asociaciones, creación de la figura jurídica de la asociación religiosa y legalización de estas asociaciones, concediéndoseles el derecho a poseer bienes para su objeto, llevar a cabo la actividad educativa y de beneficencia. ${ }^{1}$

El modelo de relación entre política y religión, surgido de las reformas mencionadas, comprendía la libertad de profesar y practicar religión siempre que no se incurriese en un delito o falta penados por la ley (art. 24 de la Constitución). Su base era „principio histórico de la separación del Estado y las iglesias“, por lo cual el Congreso no podía dictar leyes que establecieran o prohibieran religión alguna. Se mantenían, sin embargo, algunas limitaciones para impedir interferencias entre religión y política, como la educación pública laica impartida por el Estado; se excluía a los ministros religiosos del desempeño de cargos públicos y asociaciones con fines políticos, además, no podían realizar proselitismo político, oponerse a las leyes o instituciones del país o agraviar símbolos patrios en reuniones públicas. Quedaba prohibida la formación de agrupaciones políticas cuyo título se relacione con alguna confesión religiosa. Las reuniones de carácter político no podían celebrarse en los templos (art. 3 y 130 de la Constitución). Además, las autoridades federales, estatales y municipales no podían asistir con carácter oficial a ningún acto religioso de culto público (art. 25 de la Ley De Asociaciones Religiosas y Culto Público).

A pesar de la existencia de restricciones explícitas arriba mencionadas, no se evitaron las interferencias entre la esfera religiosa y política. Los presidentes del PAN - Vicente Fox (2000-2006) y Felipe Calderón Hinojosa (2006-2012) - transgredían el principio de separación Estado-Iglesia, recurriendo a símbolos religiosos, participando en ceremonias religiosas en carácter oficial y refiriéndose a creencias religiosas en su discurso. Las acciones de Fox se limitaban a gestos teatrales, ya que no cumplió con las promesas de eliminar restricciones a la libertad de la Iglesia católica. Calderón, cuyo fin político con-

1 La evolución del modelo de relaciones Estado-Iglesia católica en México ha sido objeto de mi tesis doctoral. Los resultados de la investigación se presentan en el libro Dwie władze. Studium $z$ dziejów relacji państwo-Kościót w Meksyku.
El concepto de laicidad en el contexto de cambios constitucionales recientes en materia de religión y política en México

Marta Wójtowicz-Wcisło 
Dossier América Latina: política y religión sistió en la lucha contra el crimen organizado, se abrió a colaboración con la Iglesia en materia de promoción de valores cristianos; su gabinete fue declarado como "confesional" y sujeto a la jerarquía católica. En el PAN la "fracción doctrinaria" llevó a la armonización del programa del partido con la doctrina católica en marcos de defensa de la vida y la familia. Por otro lado, los obispos se expresaban en cuestiones relacionadas con la pobreza y desigualdad, la consolidación de la democracia, el problema del crimen organizado y alzaban protestas contra iniciativas consideradas como ataques a la vida y la familia, como despenalización del aborto y legalización de matrimonios de personas del mismo sexo en el Distrito Federal. Las manifestaciones de obispos concernientes a políticas públicas también fueron consideradas como contrarias a las leyes y laicismo del Estado. No cabe duda de que fueron las reformas legislativas aprobadas en el Distrito Federal - entre las que la más importante era la despenalización del aborto en 2007 - las que crearon un ambiente que propició la iniciativa en materia de laicidad. ${ }^{2}$

\section{Reforma al artículo 40: establecimiento del Estado laico}

En reacción a actividades consideradas amenazantes a la laicidad del Estado, numerosas iniciativas del reconocimiento explícito del principio de laicidad en la Constitución fueron presentadas por diputados de diversos partidos y grupos parlamentarios (PRI, PRD, PT, Convergencia, Alternativa, Nueva Alianza) a partir del año 2006. ${ }^{3}$ El dictamen de la Comisión de Puntos Constitucionales, presentado en la Cámara de Diputados el día 11 de febrero de 2010, favorecía el objetivo de las iniciativas. La Comisión argumentaba que la reforma confirmaría el rumbo planteado por los liberales en el siglo XIX y constituía „una fórmula eficaz para la convivencia de la pluralidad, la convivencia entre religiones mayoritarias y minoritarias, y para evitar que las creencias de unos cuantos se hicieran dominantes a través de la fuerza del Estado y no de las del convencimiento y la persuasión legítima". Se subrayaba que el establecimiento de la laicidad era necesario para asegurar el respeto a la pluralidad de expresiones, cultural y religiosa, lográndose con ello un clima de paz

2 Sobre el contexto previo a la reforma, la controversia acerca de despenalización del aborto en el Distrito Federal y penalización del aborto en varios estados, véase: Salazar Ugarte P. (et al.) (2015), La República laica y sus libertades. Las reformas a los artículos 24 y 40 constitucionales, Instituto de Investigaciones Jurídicas, Serie Cultura Laica, no 4, UNAM, México, pp. 3-8.

3 Hay que subrayar que en la confección de la reforma intervinieron diversos actores políticos y sociales. La Cámara de Diputados organizó reuniones para conocer opiniones de académicos, como Roberto Blancarte, de organizaciones de sociedad civil, como Católicas por Derecho a Decidir, el Foro Intereclesiástico Mexicano y el Grupo de Información y Reproducción Elegida (Salazar et al. 2015: 8).

4 Todas las citas de los dictámenes de las Comisiones y de los debates parlamentarios provienen de los decretos de reforma respectivos, indicados en la Bibliografía. 
y tolerancia. La consolidación del principio de laicidad en el orden jurídico mexicano era considerada como una condición de la ética que debía regir la vida pública y como la mejor forma de cristalizar los derechos de libre elección de una religión o convicciones evitando que "los valores o intereses religiosos se erijan en parámetros para medir la legitimidad o la justicia de las normas y los actos de los poderes públicos, con lo cual se veda cualquier tipo de confusión entre funciones religiosas y funciones estatales, de ahí que los debates que se susciten de los órganos del Estado deban prevalecer siempre como guía de las discusiones el principio de laicidad".

En su dictamen la Comisión invocaba palabras del sociólogo Roberto Blancarte quien desarrolla el concepto de laicidad desde México. Es menester resumir en este lugar el pensamiento de Blancarte acerca de la laicidad, ya que, como veremos más adelante, el discurso de representantes de tres partidos - PRI, PRD, PT - se basa en gran medida en sus concepciones. Este autor demuestra que la construcción de un Estado laico que, más allá de separación de los ámbitos político y religioso, establezca una igualdad real y la no discriminación a partir de la autonomía de lo político frente a lo religioso, es un marco jurídico-político ideal para solucionar el problema de la libertad religiosa y combatir la discriminación religiosa. Según Blancarte, en México, como en el caso de los países de la tradición latina, la presencia de una Iglesia con el monopolio de la salvación y una hegemonía en el campo religioso llevó a una situación discriminatoria que sólo empezaría a superarse con la gestación de un Estado moderno cuya soberanía fue fundada en el pueblo y no en el poder divino. Por consiguiente, "el concepto más cercano al de laicidad, es el de soberanía popular o el de la legitimidad constitucional". La lucha entre el Estado y la Iglesia se entiende aquí en términos de eliminación de la discriminación religiosa. El establecimiento de la libertad religiosa no elimina la discriminación, pero ésta puede superarse gracias al establecimiento de la laicidad cuyos tres elementos fundamentales son: 1) el respeto a la libertad de conciencia; 2) la autonomía del Estado con respecto a las doctrinas y normas religiosas y filosóficas particulares; 3 ) la igualdad real de todos los seres humanos y la no discriminación directa o indirecta. El Estado laico es el no confesional, que no requiere de la religión como elemento de integración social, que excluye la religión de la esfera pública (Blancarte 2008: 9-13, 27-33).

A la hora de discutir la propuesta del reconocimiento explícito del principio de laicidad en el artículo 40 de la Constitución, que definía la forma del gobierno mexicano, se hicieron manifiestas diferentes maneras de entender el concepto de laicidad. En la discusión sobre el dictamen de la Comisión los representantes del PRI apoyaron la propuesta de la reforma aduciendo que, a pesar del establecimiento de la definición del Estado laico en el artículo $3^{\circ}$ de la Ley de Organizaciones Religiosas y Culto Público, "las interferencias del Estado hacia las actividades religiosas y de las actividades religiosas con pretendidas intenciones de participar en los debates públicos habían complicado la relación que, por otro lado, debe ser muy pulcra y muy libre". La laicidad,
El concepto de laicidad en el contexto de cambios constitucionales recientes en materia de religión y política en México

Marta Wójtowicz-Wcisło 
Dossier América Latina: política y religión según diputados del PRI, confirmaría la identidad y unidad de los mexicanos y constituía un elemento del constitucionalismo moderno que permitía discusión de las cuestiones de interés de la sociedad contemporánea "sin prejuicios, dogmas o asideros medievales", llevando al orden jurídico sano.

En la posición del PRD se exponían la diversidad y la pluralidad que caracterizaban a la sociedad mexicana, así como "la capacidad de los individuos para resolver por sí mismos los dilemas éticos", que implicaban necesidad de la promoción y respeto a la tolerancia, a los valores individuales o colectivos, al laicismo de las instituciones y de los espacios públicos. El PRD defendía "la autonomía moral de los individuos, una ética global de respeto a la diversidad y por la inclusión de todas y todos", sobre todo de discriminados o excluidos. Se propugnaba el laicismo como rechazo a "los regímenes teocráticos en los que una iglesia controla el poder político", "los regímenes políticos que se sirven de una religión oficial para legitimarse ideológicamente", y uso de "las creencias religiosas con fines electorales para apoyar o descalificar adversarios políticos". En la posición del PRD resonaba con la mayor fuerza la discusión sobre el aborto y los matrimonios homosexuales. La laicidad era considerada como un instrumento importante para la defensa de los derechos de las mujeres en el caso de que se limitaran por razones religiosas, desprendiéndose de ello la libertad de decisión sobre el propio cuerpo y el derecho a decidir en todas las esferas de la vida privada. El PRD acusó a la derecha de haber llevado a cabo contrarreformas de penalización del aborto en las Constituciones locales de más de la mitad de los estados del país, lo que implicaba un retroceso en el ejercicio de los derechos de las mujeres. Acusó también a los funcionarios públicos de nivel federal de haber abandonado la lucha contra la pandemia del VIH/sida y de haber desatendido la salud de los jóvenes "por no entender que las concepciones religiosas no pueden determinar las acciones de salud que lleve a cabo el Estado". Se puso de relieve que la laicidad plasmada en la Constitución permitiría abordar asuntos - tales como el derecho al aborto, a la salud reproductiva, el papel de la religión en los medios de comunicación y en las instituciones públicas, la censura, la línea entre lo público y lo privado - de manera racional, de conformidad a las circunstancias concretas de los mexicanos y con exclusión de criterios religiosos. Además, reafirmaría la obligación del Estado para velar que la educación respondiera al principio de igualdad, que fuera antidogmática y científica, formando individuos capaces de ejercer su autonomía moral. Se adoptaba la definición de laicidad desarrollada por Blancarte: se trataba de construir un régimen de convivencia social cuyas instituciones políticas estuvieran legitimadas por la soberanía popular y que excluyera a las religiones de la esfera pública para permitir una adopción de quien así lo decidiera en el ámbito personal y particular. Los diputados del PRD denunciaban acciones del presidente Calderón quien, al colocar por delante de las leyes mexicanas las creencias religiosas, ponía en riesgo la cohesión social. Se acusaba al presidente de sostener que el consumo de drogas en el país había aumentado por la falta de rezos (y no por la falta de una polí- 
tica pública eficaz); de afirmar equivocadamente que la Constitución incluía explícitamente conceptos que sólo son parte de los edictos de su religión; de confundir "pecado" con "delito", lo cual amenazaba el Estado laico. Asimismo, en clara alusión a visitas de los presidentes mexicanos en Vaticano, se denunciaba que se habían arrodillado "en frente al jefe de otro Estado" poniendo con ello en riesgo el Estado de derecho. Por consiguiente, se estimaba que la aprobación de la reforma era urgente.

La reforma fue apoyada también por el PT. Sus miembros denunciaban "la presencia de una iglesia católica militante, que por un lado promueve reformas constitucionales y legales en los estados y por otro, se opone a otras reformas" y que quiere apoderarse de las instituciones del Estado. La reforma propuesta se entendía aquí como "reafirmación del principio de la separación entre la iglesia y el Estado" y la laicidad, de acuerdo con las indicaciones de Blancarte, como legitimidad política fundada exclusivamente en la soberanía popular, la defensa y garantía de los derechos humanos y no en la ley divina o la ley eterna. El Estado laico implicaba "el mantenimiento y la defensa de un espacio público secularizado, que debe estar orientado por el interés general"; "la existencia de una moral pública no sustentada en ningún credo o convicción religiosa, sino una moral pública basada en el consenso, en el pluralismo, en la tolerancia de los ciudadanos"; política libre "de cualquier contaminación de carácter religioso o que tenga vínculo con alguna creencia dominante"; "libertad filosófica, libertad de conciencia, libertad para creer o no creer (...), que no se puede imponer a nadie por la fuerza".

Igualmente que el PRD, el PT y el Grupo Parlamentario de Convergencia denunciaban históricas y recientes intromisiones de la Iglesia católica en los asuntos políticos, que violaban leyes mexicanas y la vida laica en la República. Asimismo, se denunciaba la simpatía de la Iglesia católica a favor del PAN, el uso de la religión con fines políticos y rompimiento del principio de laicidad por altos funcionarios del gobierno, miembros de este partido.

El concepto del Estado laico según diputados del PAN difería significativamente de la posición de otros partidos, acercándose más bien a la posición del Episcopado Mexicano, que se examina a continuación. Se indicaba que la separación de la Iglesia y el Estado estaba históricamente concluida, por lo cual era "inútil e inoportuno intentar revivir querellas decimonónicas" que los mexicanos consideraban superadas. La laicidad, según diputados del PAN, se basaba en dos grandes pilares: autonomía e independencia del poder civil respecto al poder clerical y la libertad de creencia. El Estado laico era aquél que defendía "la separación institucional entre religión y política, manteniendo, en todo momento, la neutralidad del Estado respecto a las demás religiones, así como el respeto a la cultura e idiosincrasia del país en cuestión". Se subrayaba que muchas naciones, respetando el principio de la laicidad, "no rebajaban la religión al nivel de un hecho intrascendente, meramente privado", porque "el Estado laico no puede cerrar los ojos ante el fenómeno religioso que se presenta como un hecho cultural, tradicional o mayoritario en una determinada
El concepto de laicidad en el contexto de cambios constitucionales recientes en materia de religión y política en México

Marta Wójtowicz-Wcisło 
Dossier América Latina: política y religión nación (...). Una laicidad que desconozca el hecho religioso o que descalifique toda referencia procedente de algún principio religioso o filosófico representaría una posición política, rígidamente doctrinaria, totalitaria y abstracta." Por consiguiente, la neutralidad del Estado no había de traducirse en "una actitud antirreligiosa, un ateísmo político o totalitarismo ideológico". Citando a Antonio Molina Melia, se indicaba que el Estado laico no hacía suya ninguna religión, ninguna irreligión, incluyendo el ateísmo o filosofía inmanentista, pero al margen de cualquier identidad religiosa, ideológica o confesional, debería proveer un ideal de ciudadanía y bien común. El Estado laico no debería "limitarse a adoptar una benévola tolerancia frente al hecho religioso" sino "establecer un vínculo recíproco y respetuoso sobre en qué construir una comunidad política y solidaria acogiendo a todos los ciudadanos por igual, creyentes o no, para la consecución del bien común." Se consideraba insano e incompatible con el Estado laico el "negar a ninguna comunidad de creyentes y a quienes les representan legítimamente el derecho a pronunciarse sobre cuestiones de cualquier tipo que están en manos de los legisladores y juristas y que interpelen a sus conciencias." El Estado que se erigiera "en fuente última de valor" y pretendiera "acallar la voz de sus Iglesias" sería un Estado totalitario. La diversidad de opiniones representaba la libertad de expresión de los ciudadanos, por lo cual no debería considerarse como una ofensa al Estado, sino como un sano pluralismo político. Los únicos límites de la libertad religiosa eran marcados por el respeto a las normas jurídicas vigentes. El PAN apoyaba la reforma, pero con advertencia de que la laicidad imponía al Estado una doble obligación, tanto pasiva como activa. La primera implicaba que el Estado mexicano debía abstenerse de imponer creencias religiosas o restringir las libertades de toda persona; la segunda consistía en expedir las normas que tutelaran en forma eficaz dicha garantía fundamental. Tal sentido de laicidad estaba de acuerdo con compromisos internacionales vinculatorios para México, precisamente con lo establecido en el artículo 12 de la Convención Americana de los Derechos Humanos. El PAN solicitó que esta adición fuera integrada en el dictamen, pero la Cámara de Diputados rechazó esta propuesta.

Resumiendo, el concepto de laicidad propugnado por el PRI, PRD y PT acentuaba la soberanía del pueblo y la deliberación racional basada en ciencia en el proceso de acordar las bases del orden político-social. Aduciendo el respeto y un trato igual a todas las asociaciones religiosas, se las excluía a la vez de la participación en la vida política y espacio público, negando la presencia y la referencia a creencias religiosas en la esfera política. Al contrario, la posición del PAN comprendía que las creencias religiosas y filosóficas fueran aceptadas en el debate público. El Estado debería respetar la identidad religiosa de la nación, tomando en cuenta la representatividad de las asociaciones religiosas y aprovechando su aportación al bien común. La opinión de los creyentes y sus representantes debería ser escuchada por los legisladores en una sociedad plural.

La reforma al artículo 40 que establecía explícitamente el carácter laico del Estado, con la exposición de motivos que la acercaba más bien a la posición 
del PRI, PRD y PT, fue aprobada en la Cámara de Diputados por la mayoría de los votantes (con 363 votos en pro; sólo un diputado votó contra la reforma; ocho votos de abstención) el 11 de febrero de 2010. Como acertadamente señalan varios autores (Salazar et al. 2015: 14), la reforma al artículo 40 consolidaba las disposiciones existentes en el ordenamiento politico-jurídico, confirmando la tradición liberal mexicana del siglo XIX. Al mismo tiempo, dichas disposiciones se consideraban insuficientes para evitar influencia de la religión en el poder público.

\section{Postura del Episcopado Mexicano}

La Arquidiócesis de México criticó la reforma al artículo 40 señalando que el concepto de laicidad tenía en México un sentido negativo y que llevaría como destinatario a la Iglesia católica, en particular y en general. La reforma fue considerada represiva a las Iglesias en lo que tocaba a la libertad de expresión y a los ciudadanos en lo que tocaba a la libertad religiosa, siendo incompatible con la Convención Americana de los Derechos Humanos. El vocero de la Arquidiócesis de México declaró que los ministros de culto no eran interesados en política activa, pero cuando se aprobaban las leyes que afectaban la moral tenían que opinar. Además, consideró que al apoyar la reforma el PAN se situaba como enemigo de la Iglesia.

El Episcopado Mexicano ha propugnado el concepto de "laicidad positiva, abierta", fundada en autonomía del orden temporal y del orden espiritual, que favorecía "una sana colaboración y un espíritu de responsabilidad compartida". Los obispos percibían el cambio de época, consistente en cuestionamiento de los grandes referentes de la cultura y de la vida cristiana, que afectaba la valoración del hombre y su relación con Dios, mientras que nuevas expresiones culturales establecían sus criterios de decisión "apoyados a menudo exclusivamente en respuestas científicas parciales y en visiones limitadas de la realidad, en descredito de toda consideración religiosa." El Episcopado advertía contra el "laicismo radical" que buscaba "eliminar un horizonte trascendente de todo proyecto de futuro, provocando con ello un enorme vacío", identificándolo como la mayor amenaza a la cultura. El laicismo intolerante que buscaba disminuir libertades y restringir espacios de expresión era enemigo más peligroso del Estado laico y no tenía cabida en una sociedad democrática. Según los obispos, era preciso confirmar un auténtico sentido de laicidad, o sea "reconocer e impulsar el derecho de todos los ciudadanos a vivir, en lo privado y en lo público, conforme a sus convicciones de conciencia en materia religiosa, con entera libertad". De acuerdo con sus palabras, la "laicidad del Estado" no significa "la promoción de ideologías antirreligiosas o areligiosas, que violan el derecho a la libertad religiosa bajo el pretexto de una supuesta «neutralidad» estatal", sino debe ser entendida como "la aconfesionalidad basada en el respeto y promoción de la dignidad humana y, por lo tanto, en el reconocimiento
El concepto de laicidad en el contexto de cambios constitucionales recientes en materia de religión y política en México

Marta Wójtowicz-Wcisło 
Dossier América Latina: política y religión explícito de los derechos humanos, particularmente del derecho a la libertad religiosa." Ésta se definía como "derecho de la persona que abraza no solo a los creyentes sino aun a los no creyentes en su derecho a vivir con plena libertad las opciones que en conciencia se realizan sobre el significado y el sentido último de la vida. El ejercicio de esta libertad incluye tanto la vida privada como la pública, el testimonio individual y la presencia asociada, con el único límite del respeto al derecho de terceros." (Conferencia del Episcopado Mexicano 2010: 29-31). Restringir la libertad religiosa al culto o impedir su ejercicio en campos como la educación pública y la participación cívico-política es considerado aquí como contrario a la dignidad humana y Estado democrático. El Estado debe respetar a todas las Iglesias y a los creyentes, "con el único límite que establecen las exigencias de la justicia y del bien común." Este respeto requiere reconocimiento igualitario de todas Iglesias en cuanto instituciones. Sin embargo, como afirman los obispos, no todas poseen la misma representatividad, ya que su manera y grado de aportación al bien común son distintos, lo cual debería tomarse en cuenta en justicia. Un auténtico Estado de derecho tampoco debe ser indiferente o neutral en cuanto a los valores fundamentales de la persona, la familia y la cultura: "si bien es cierto que un elemento esencial de una sociedad libre y plural es la tolerancia también es cierto que la tolerancia que acepta acríticamente cualquier cosa se vuelve en contra de ella misma. Por lo tanto, es preciso respetar los fundamentos inviolables que permiten que una sociedad plural no se derrumbe. Estos fundamentos no son otros que los derechos y deberes que brotan de la inalienable dignidad humana" (Conferencia del Episcopado Mexicano 2000: 274-282).

Asimismo, los obispos declaraban aceptación de la autonomía del poder religioso y político, a la vez que reconocían la necesidad de colaboración entre ellos y su propio encargo de formar conciencia y fomentar actividad de ciudadanos, así como orientar fundamentos morales de la sociedad de acuerdo con exigencias de la justicia, la dignidad humana y la identidad cristiana de la nación. La laicidad se concebía como el respeto del Estado a la libertad religiosa de los ciudadanos, limitada solamente por el respeto al derecho de terceros. De acuerdo con disposiciones del Concilio Vaticano II, el Episcopado Mexicano reclamó repetidas veces el reconocimiento de plena libertad religiosa ${ }^{5}$ (Corral Martín 2009).

Vale la pena mencionar aquí que en su camino a México el 23 de marzo de 2012, el papa Benedicto XVI dio cuenta de "cierta esquizofrenia" de algunos católicos, que en la esfera individual eran creyentes, pero en la vida pública se-

5 Particularmente, entre tareas pendientes con asociaciones religiosas se indicaban: reconocimiento de la objeción de conciencia en el sistema jurídico mexicano; desregulación administrativa en el ámbito de la aplicación de la Ley de Asociaciones Religiosas y Culto Público; ayuda espiritual en centros de salud, de readaptación social y de asistencia del sector público (sin tantos requisitos como los que se tienen al momento); posibilidad de poseer medios masivos de comunicación; supresión de la disposición legal que limita la asistencia de las autoridades a actos religiosos de culto público. 
guían caminos que no correspondían a los valores del Evangelio. El papa insistió en la necesidad de superar esta esquizofrenia a través de la doctrina social de la Iglesia, por educación que incluyera una moral pública, la cual debería ser una moral razonable que pudieran compartir también los no creyentes.

\section{Reforma al artículo 24: ampliación de la libertad religiosa}

La segunda reforma constitucional, propuesta en la materia que nos interesa en este artículo, respondía a los reclamos de la Iglesia. La iniciativa del cambio fue presentada por el PRI en marzo de 2010 (o sea un mes después de aprobación de la reforma al artículo 40 por la Cámara de Diputados): se proponía revisar y actualizar el contenido del artículo 24 de la Constitución, por considerarlo incipiente o incompleto, con el fin de ampliar el sentido de la libertad religiosa garantizada en este artículo. El PRI quería ampliar el derecho a la libertad de religión reconocida en el artículo 24, concibiéndolo como „la libertad de tener o adoptar, o no tener ni adoptar, la religión o las creencias de su elección, así como la libertad de manifestar su religión o creencias, individual o colectivamente, tanto en público como en privado, mediante el culto, la celebración de ritos, las prácticas, la difusión y la enseñanza, siempre que no constituyan una falta o un delito sancionado por la ley". Preveía también establecer que el Estado respetaría la libertad de los padres para garantizar que los hijos recibieran la educación religiosa de acuerdo con sus convicciones, así como suprimir el inciso que sólo excepcionalmente actos religiosos se celebraban fuera de los templos de acuerdo con la ley reglamentaria.

El PRI argumentaba que el sistema mexicano carecía de precisión de un concepto de Estado laico positivo, limitando la posibilidad de regular adecuadamente la libertad religiosa. En el régimen jurídico mexicano subsistían las disposiciones restrictivas y "anticlericales", pero sobre todo que infringían el contenido de derechos fundamentales, sin explicación alguna (como ejemplos se indicaban: restricción para difundir actos de culto en medios de comunicación masiva, que exige la previa autorización de la Secretaría de Gobernación, equiparado a una censura previa; restricciones a los derechos fundamentales en términos del artículo 130 de la Constitución). Según el PRI, las restricciones a la libertad religiosa no debían tener más límites que el carácter laico del Estado y deberían quedar superadas con la adopción de un derecho a la libertad religiosa, por implicar lo contrario "una postura «fundamentalista», «anticlerical», o en el mejor de los casos «ideológica» que ubica al Estado en una posición de parcialidad inconveniente para cualquier régimen democrático contemporáneo". La limitación del derecho se veía también como intromisión que violaba la separación del ámbito estatal y religioso. Ahora bien, la ampliación de la garantía seguiría estándares del „Estado constitucional de derecho democrático”, adoptados por países occidentales. En tal sistema, „el Es-
El concepto de laicidad en el contexto de cambios constitucionales recientes en materia de religión y política en México

Marta Wójtowicz-Wcisło 
Dossier América Latina: política y religión tado adopta una postura activa para garantizar y hacer efectivo el contenido de los derechos fundamentales y se despoja del ropaje de un Estado neutral o contemplativo, pero debe quedar claro que esa acción jamás implica la restricción del contenido de los derechos. En otros términos, se tiene un Estado imparcial para respetar el contenido de los derechos, pero militante o activo para garantizarlos".

Es interesante que el concepto de laicidad que emanaba de la iniciativa del PRI hasta cierto punto contradijera la posición que este partido había defendido en la discusión de la reforma del artículo 40 y concordase con las tesis propugnadas por el PAN, particularmente, con el concepto de doble obligación - pasiva y activa - del Estado laico. El PRI indicaba que el hecho de incorporarse y garantizarse el derecho humano de la libertad religiosa, sin limitación de ninguna índole, armonizaría derecho mexicano con pactos internacionales de los que México era parte y continuaría el camino trazado en 1992, ya que la Ley de Asociaciones Religiosas y Culto Público de 1992 comprendía no sólo la libertad de practicar el culto, sino también la libertad de manifestar las ideas religiosas y la de asociarse o unirse pacíficamente con fines religiosos. Quien debería beneficiarse de la reforma, como afirmaba el PRI, eran las personas y no las jerarquías de las Iglesias. Con la reforma el concepto de Estado laico en sentido positivo quedaría ligado en forma indisoluble con el derecho de libertad religiosa.

La propuesta del PRI recibió aprobación de la Comisión de Puntos Constitucionales que sometió su dictamen a la discusión de diputados el 15 de diciembre de 2011. La Comisión subrayaba la necesidad de armonizar el derecho mexicano con los estándares del derecho internacional. Además, ponía de relieve que todo Estado laico, por su carácter de imparcialidad, debería reconocer la libertad religiosa, pues no hacerlo revelaría la actitud de un Estado anticlerical que lo alejaría de su laicidad: „El Estado laico no ignora ni desprecia la religiosidad del pueblo manifestada en la diversidad de creencias, antes bien la asume como un hecho social o cultural que toma en cuenta al momento de legislar o gobernar, para que la norma tenga eficacia”. La Comisión indicó que, a la luz del artículo revisado, se requeriría también la revisión de los artículos 3, 5, 27 y 130, así como de leyes secundarias. Sin embargo, la Comisión convino que, por el momento, sólo existían condiciones para concretar la reforma al artículo 24 de la Constitución que debería establecer derecho a la libertad de conciencia y de religión, incluyendo el derecho de practicar, individual o colectivamente, tanto en público como en privado, las ceremonias, devociones o actos del culto respectivo, siempre que no constituyeran un delito o falta sancionada por la ley. Hay que subrayar que no se apoyó la adición propuesta por el PRI en cuanto a la libertad de manifestar la religión mediante difusión y enseñanza; ni tampoco en cuanto al respeto a la libertad de los padres para garantizar que los hijos recibieran la educación religiosa. Es importante también que la Comisión decidiera hacer al texto del artículo 24 la siguiente adición: „nadie podrá utilizar los 
actos públicos de expresión de esta libertad con fines políticos, de proselitismo o de propaganda política“.

El debate sobre el dictamen careció de fondo y se centró en cuestiones procedimentales, al contrario que en el caso de la reforma al art. 40. En el curso del debate los diputados del PT y PRD alegaban que la reforma constituía un regalo de Enrique Peña Nieto (entonces candidato presidencial del PRI), PRI y PAN para la Iglesia, relacionado con el proceso electoral (elecciones presidenciales en julio de 2012) y visita del papa Benedicto XVI en México (planeada para el marzo de 2012), y que su objetivo era el aumento del poder de la Iglesia católica, con detrimento de laicidad del Estado. La reforma fue calificada como de coyuntura y con un propósito político electoral evidentemente claro. Se indicaba que el PRI traicionó sus principios históricos. Además, algunos miembros del PRD denunciaban violaciones en el procedimiento y se preocupaban de la presión inusitada, indicando que una reforma tan importante no debería aprobarse en un solo día, el último de aquel período de sesiones, sin consultas sociales. Sin embargo, la reforma al artículo 24 de la Constitución de acuerdo con el dictamen de la Comisión fue aprobada por la Cámara de Diputados el mismo día 15 de diciembre de 2011 (con 199 votos de la mayoría representada por el PAN y el PRI, 58 en contra y tres de abstención).

\section{Protesta contra la reforma al artículo 24}

La reforma al art. 24 suscitó una polémica que no acompañó a la reforma al art. 40. Diversas organizaciones civiles (algunas, como Foro Cívico México Laico, surgidas coyunturalmente) y religiosas, así como funcionarios públicos y académicos manifestaron su preocupación por falta de transparencia en el proceso de elaboración y aprobación de la reforma, rechazando el contenido de la misma y exigiendo su rechazo por el Senado, por medio de marchas multitudinarias y firmas de protestas, entre otras acciones.

Se alegaba que la modificación propuesta era un regalo de la clase política para congraciarse con el papa, vulneraba el Estado laico y las libertades de los mexicanos, y privilegiaba a la Iglesia católica. Principalmente, se advertía que la reforma posibilitaría enseñanza religiosa en las escuelas públicas y posesión de medios de comunicación masiva por asociaciones religiosas, pero también que gracias a ella se quería lograr cargos de elección popular para sacerdotes y abrirles posibilidad de intervenciones políticas. Los críticos señalaron que la reforma al art. 40, aprobada hacía dos años, debería ser avalada antes en el Senado. ${ }^{6}$ Es interesante que las voces de protesta se concentraran en temas de enseñanza religiosa y medios de comunicación, a pesar de que el párrafo de la iniciativa original que hacía referencia a la educación religiosa, así como

6 Véase por ejemplo: „Excelsior” de 26.08.2012, „Animal Político” de 25.03.2012, “Proceso” de 27.01.2012 y 14.01.2013, “La Jornada” de 03.07.2013.
El concepto de laicidad en el contexto de cambios constitucionales recientes en materia de religión y política en México

Marta Wójtowicz-Wcisło 
Dossier América Latina: política y religión el fragmento sobre ejercicio de libertad por medio de difusión y enseñanza fueron retirados por la Comisión.

En la protesta contra la reforma alzaron su voz Iglesias evangélicas entre las que destacó la Luz del Mundo que, de acuerdo con palabras de Bernardo Barranco, "mostró verdadero «músculo», movilizando en las calles a sus seguidores y no seguidores, y adentrándose en toda instancia académica y política posible" ("Excelsior" 07.03.2016). La Luz del Mundo emitió una opinión en la que señalaba que el trasfondo de la reforma "consiste en la manipulación de la noción de libertad religiosa", porque se abandonaba su comprensión como derecho humano; con ello la Iglesia católica buscaba "resucitar antiguos privilegios": instrucción religiosa en las escuelas públicas; participación del clero en política electoral; instalación de capellanías en el Ejército y la Marina; subsidio estatal para sueldos de los ministros de culto, además de la posesión y control de medios de comunicación electrónicos, entre otros." Según la Luz del Mundo, el propósito de la reforma era el desmantelamiento del Estado laico con el cambio de sentido de la libertad religiosa, ya que la Comisión de Puntos Constitucionales en su dictamen anticipaba una revisión de los artículos 3, 5, 27 y 130 de la Constitución. Se advertía contra la cancelación de la educación laica, indicando que la Comisión reconocía la posibilidad de educación religiosa en las escuelas públicas; en opinión contraria de la Luz del Mundo, la libertad religiosa bien entendida no obligaba al Estado a fungir como catequista o instructor al servicio de una determinada confesión". Se protestaba también contra el reconocimiento por parte de la Comisión del derecho a la comunicación de las convicciones religiosas mediante la utilización de medios de comunicación social. La Luz del Mundo exigía establecimiento de la laicidad del Estado considerando que sólo en sus marcos era posible la libertad religiosa y se rechazaba el uso de ésta como fundamento de privilegios (La Luz del Mundo 2011).

La oposición y movilización social contra la reforma se mantuvo durante todo el proceso de aprobación e incluso después. ${ }^{7}$ Hay que poner de relieve que el proceso de aprobación por los congresos fue en este caso más largo de lo habitual y que seis estados rechazaron la reforma. Como indica Barranco, las principales reticencias para aprobarla en las diferentes entidades emanaron del propio PRI, de sus corrientes liberales y masónicas (“La Jornada” 03.07.2013).

7 En contexto de protesta contra la reforma en la Universidad Nacional Autónoma de México, en enero de 2013, se creó la Cátedra extraordinaria „Benito Juárez” cuya finalidad primordial es "fomentar el estudio y la difusión de la laicidad en México". Véase la página de la Cátedra: http://catedra-laicidad.unam.mx. Vale la pena hacer mención del hecho que en julio de 2013 el exdiputado priista, Manuel Jiménez Guzmán, informó la prensa sobre creación de Laica Internacional México, una nueva organización masónica cuyo objetivo sería promover la "cultura de la laicidad" ante los embates de la jerarquía católica. Véase: R. Vera, Surge nueva organización masónica: busca enfrentar al clero, http://www.proceso.com.mx/348456/surge-nueva-organizacion-masonica-busca-enfrentar-al-clero. 


\section{Aprobación por el Senado}

Es interesante que ambas reformas analizadas en este artículo fueran discutidas en el Senado el mismo día 28 de marzo de 2012 (la del artículo 24 tres meses después de haber sido aprobada en la Cámara de Diputados y la del artículo 40 después de casi dos años de haber recibido esta aprobación - el hecho que la oposición calificó como "rescatarlo de la congeladora”). Veamos algunos argumentos expuestos en el curso de los debates en el Senado.

En el dictamen de las Comisiones Unidas de Puntos Constitucionales y de Estudios Legislativos del Senado acerca de la reforma al artículo 40, se mantuvieron los motivos aducidos por la Comisión dictaminadora de la Cámara de Diputados. Es interesante ver que la posición del PRI en la discusión en el Senado se precisaba esta vez acentuando la neutralidad del Estado (o su obligación pasiva) en materia de confesiones religiosas y de convicciones éticas, filosóficas e ideológicas de las personas: el Estado no debe imponer el cumplimiento coactivo de una norma moral o de una forma de pensar, ni sancionar o disuadir a nadie en cuanto a ese tipo de creencias y de convicciones. Como ejemplo de incumplimiento del principio de laicidad se indicaba que a Joseph Ratzinger se le hubiera dado recepción de Jefe de Estado y que el Presidente de la República hubiera participado en actos de culto en público. Se subrayaba a la vez que el objetivo de la pugna por laicidad era "mantener una convicción firme en la defensa del conocimiento científico y del respeto a quienes no profesan religión alguna”. La reforma fue aprobada por 97 votos en pro, 3 en contra y uno de abstención.

Ahora bien, las Comisiones del Senado en su dictamen acerca de la reforma del artículo 24 se inclinaban por el criterio de "hacer posible la convivencia de todas las ideologías posibles", sin dar preferencia a ninguna. Asimismo, se indicaba que los límites del derecho quedaban marcados con la previsión de que los actos públicos de expresión de la libertad religiosa no se utilizaran con fines políticos, para evitar intentos de influir en la conciencia de las personas con el fin de cambiar sus preferencias políticas o capitalizar políticamente la realización de actos religiosos.

Es muy importante que la Comisión del Senado no estaba de acuerdo con la resolución de la Comisión de la Cámara de Diputados, que la reforma del artículo 24 requiriera revisión de otros artículos constitucionales y leyes secundarias; por el contrario, éstos se deberían mantener incólumes por considerarlos principios fundamentales del derecho mexicano. De este modo, se quería confirmar el carácter imparcial y neutral del Estado en la materia de religión, rechazando posibilidad de consentimientos a favor de asociación religiosa alguna.

Nuevamente, fueron diputados del PRD quienes protestaron contra la reforma con la mayor fuerza, aduciendo tres argumentos principales: la inexistente necesidad de la reforma al cuerpo normativo constitucional (porque el texto existente reconocía la libertad religiosa); la falta del interés social y res-
El concepto de laicidad en el contexto de cambios constitucionales recientes en materia de religión y política en México

Marta Wójtowicz-Wcisło 
Dossier América Latina: política y religión

paldo ciudadano; e indebido y atropellado proceso legislativo. La ampliación explícita del contenido del derecho - según el PRD - provocaría enfrentamientos indebidos relacionados con el objeto de conciencia. Además, se alegaba que la reforma propuesta abriría puertas a concesiones a favor de la Iglesia mayoritaria. La reforma fue aprobada por 72 votos en pro y 35 votos en contra.

\section{Conclusiones}

Podría considerarse que, al someter a la discusión del Senado las dos reformas el mismo día, se quisiera satisfacer o conciliar distintos modos de concebir la laicidad, existentes en México, o bien, de acuerdo con la acepción del PAN, reconocer la doble obligación del Estado laico. Sin embargo, más bien parece válida la constatación de que prevaleció la obligación pasiva (o negativa) del Estado laico como tal, y que el Legislador o Soberano confirmó la tradición jurídica mexicana en el ámbito de relación entre religión y política, de excluir la esfera política de influencia de creencias religiosas. Como hemos visto, la reforma que establece explícitamente el carácter laico de la Republica surgió a iniciativa de diversos partidos, fue apoyada por la mayoría abrumadora en el Congreso y no resultó en la protesta de ciudadanos, pero sí de la Iglesia católica que dio cuenta del sentido negativo del concepto de laicidad en México. $\mathrm{Al}$ contrario, la propuesta de ampliar la libertad religiosa engendró la intensa protesta, resultando en una reforma que podría calificarse como insignificante. Por un lado - y de acuerdo con postulados de los jerarcas de la Iglesia católica, del reconocimiento de plena libertad religiosa que abarque la esfera pública - se reconoció la libertad de ejercer actos de culto en público. Sin embargo, como hemos demostrado, el reconocimiento de la libertad religiosa quedaba limitado, ya que el Legislador no consintió en reconocer la libertad de manifestar la religión mediante difusión o enseñanza. Además, se restringió la libertad de la manifestación de creencias religiosas del contexto político, confirmando asimismo la tradición jurídica mexicana. Esta última restricción demuestra perfectamente la importancia de las interferencias política-religión en México y refleja el mantenimiento de la tendencia de separar la esfera política y religiosa, contra el sentido del laicismo abierto, contra la posición del PAN y de la Iglesia católica.

\section{Bibliografía}

Aranda E., Sacrofobia...contra el 24, 26.08.2012, “Excelsior”, disponible en: http://www.excelsior. com.mx/opinion/2012/08/26/enrique-aranda/855562, fecha de consulta: 22.08.2016.

Barranco B., La reforma al 24 constitucional, una vergüenza, 03.07.2013, "La Jornada", disponible: http://www.jornada.unam.mx/2013/07/03/opinion/021a1pol, fecha de consulta: 22.08.2016. 
Barranco B., "República laica en riesgo"; Barranco advierte revancha del clero, 07.03.2016, "Excelsior", http://www.excelsior.com.mx/nacional/2016/03/07/1079296, consulta: 20.07.2016.

Blancarte R. (2008), Libertad religiosa, estado laico y no discriminación, Cuadernos de la igualdad 9, Consejo Nacional para Prevenir la Discriminación, México DF.

Conferencia del Episcopado Mexicano, Carta pastoral Del encuentro con Jesucristo a la solidaridad con todos, 25.03.2000, disponible en: http://www.vicariadepastoral.org.

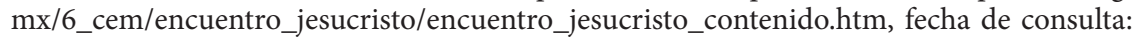
19.07.2016.

Conferencia del Episcopado Mexicano, Carta pastoral Conmemorar Nuestra Historia desde la Fe, para Comprometernos Hoy con Nuestra Patria, 01.10.2010, disponible en: http://www. vicariadepastoral.org.mx/assets/carta_pastoral_bicentenario.pdf, fecha de consulta: 19.07.2016.

Corral Martín M., Las Asociaciones Religiosas y su participación en la sociedad mexicana, 14.08.2009, disponible en: http://www.caritasmexicana.org/comunicacion/noticias/211las-asociaciones-religiosas-y-su-participacion-en-la-sociedad-mexicana, fecha de consulta: 19.07.2016.

Constitución Política de Los Estados Unidos Mexicanos, texto vigente, disponible en: http:// www.diputados.gob.mx/LeyesBiblio/htm/1.htm, fecha de consulta: 25.07.2016.

Denuncian en la UNAM embestida del clero contra el Estado laico, 14.01.2013, "Proceso", disponible en: http://www.proceso.com.mx/330608/denuncian-en-la-unam-embestidadel-clero-contra-el-estado-laico, fecha de consulta: 20.08.2016.

Decreto por el que se reforma el artículo 24 de la Constitución Política de los Estados Unidos Mexicanos, 19.07.2013, disponible en: http://www.diputados.gob.mx/sedia/biblio/prog leg/079_DOF_19jul13.pdf, fecha de consulta: 23.07.2016.

Decreto por el que se reforma el Artículo 40 de la Constitución Política de los Estados Unidos Mexicanos, 30.11. 2012,

disponible en:http://www.diputados.gob.mx/LeyesBiblio/proceso/lxii/006_DOF_30nov12. pdf, fecha de consulta: 23.07.2016.

Entrevista concedida por el Santo Padre Benedicto XVI a los periodistas durante el vuelo hacia México, 23.03.2012, disponible en: http://www.vatican.va/holy_father/benedict_ xvi/travels/2012/documents/trav_ben-xvi_messico-cuba_20120323_sp.html, fecha de consulta: 25.07.2016.

Evangélicos mexicanos rechazan reforma al artículo 24 de la Constitución, 02.02.2012, disponible en: http://www.noticiacristiana.com/sociedad/iglesiaestado/2012/02/evangelicos-mexicanosrechazan-reforma-al-articulo-24-de-la-constitucion.html, fecha de consulta: 22.08.2016.

Guillén P., Precisiones sobre las reformas para la "libertad religiosa", 25.03.2012, "El Animal Político", disponible en: http://www.animalpolitico.com/2012/03/precisiones-sobre-lasreformas-para-la-libertad-religiosa/, fecha de consulta: 22.08.2016.

La Luz del Mundo (2011), El trasfondo de la reforma al artículo 24 constitucional, 11.12.2011, disponible en: http://www.lldm.org/es/noticias/pagina.php?id=292\#, fecha de consulta: 22.08.2016.

Ley De Asociaciones Religiosas y Culto Público, 15.07.1992. disponible en: http://www. diputados.gob.mx/LeyesBiblio/pdf/24_171215.pdf, fecha de consulta: 20.07.2016.

Mandujano I., Religiosos y masones de Chiapas rechazan reforma sobre libertad de culto, 27.01.2012, "Proceso", disponible en: http://www.proceso.com.mx/296275/religiosos-ymasones-de-chiapas-rechazan-reforma-sobre-libertad-de-culto, fecha de consulta: 20.08.2016.
El concepto de laicidad en el contexto de cambios constitucionales recientes en materia de religión y política en México

Marta Wójtowicz-Wcisło 
Dossier América Latina: política y religión
Moreno-Bonett M., Álvarez De Lara R. (coord.) (2012), El Estado laico y los derechos humanos en México: 1810-2010, 2 tomos, UNAM, México.

Salazar Ugarte P. (et al.) (2015), La República laica y sus libertades. Las reformas a los artículos 24 y 40 constitucionales, Instituto de Investigaciones Jurídicas, Serie Cultura Laica núm. 4, UNAM, México.

Vázquez R. (2008), Laicidad, religión y deliberación pública, "Doxa. Cuadernos de Filosofía del Derecho", vol. 31, pp. 661-672.

Vera R., Solicitan juicio político contra legisladores por aprobar la reforma religiosa, 03.04.2012, "Proceso", disponible en: http://www.proceso.com.mx/303188/solicitan-juicio-politico-contralegisladores-por-aprobar-la-reforma-religiosa, fecha de consulta: 20.08.2016.

Vera R., Surge nueva organización masónica: busca enfrentar al clero, 26.07.2013, "Proceso", disponible en: http://www.proceso.com.mx/348456/surge-nueva-organizacion-masonicabusca-enfrentar-al-clero, fecha de consulta: 20.08.2016.

Wójtowicz-Wcisło M. (2016), Dwie władze. Studium z dziejów relacji państwo-Kościót w Meksyku, Universitas, Kraków. 